\title{
The U.S. National Library of Medicine and standards for electronic health records: One thing led to another
}

\author{
Clement J. McDonald ${ }^{\mathrm{a}, *}$ and Betsy L. Humphreys ${ }^{\mathrm{b}}$ \\ ${ }^{a}$ U.S. National Library of Medicine, USA \\ ${ }^{\mathrm{b}}$ U.S. National Library of Medicine (retired), USA
}

\begin{abstract}
When Donald A.B. Lindberg M.D. became Director in 1984, the U.S. National Library of Medicine (NLM) was a leader in the development and use of information standards for published literature but had no involvement with standards for clinical data. When Dr. Lindberg retired in 2015, NLM was the Central Coordinating Body for Clinical Terminology Standards within the U.S. Department of Health and Human Services, a major funder of ongoing maintenance and free dissemination of clinical terminology standards required for use in U.S. electronic health records (EHRs), and the provider of many services and tools to support the use of terminology standards in health care, public health, and research. This chapter describes key factors in the transformation of NLM into a significant player in the establishment of U.S. terminology standards for electronic health records.
\end{abstract}

Keywords: Donald A.B. Lindberg M.D., U.S. National Library of Medicine, logical observation identifiers names codes, RxNorm, systematized nomenclature of medicine, electronic health records, health information exchange

\section{Introduction}

When Donald A.B. Lindberg M.D. became Director in 1984, the U.S. National Library of Medicine (NLM) was a leader in the development and use of information standards for published literature [1]. He viewed NLM's work on publication standards as highly appropriate for a national library and encouraged it [e.g., 2-4]. Although Dr. Lindberg saw electronic health records as essential and inevitable, he had no plan to extend NLM's standards efforts to clinical data. In 1985, when offered a possible opportunity to take over responsibility for maintaining the Systematized Nomenclature of Medicine (SNOMED) from the College of American Pathologists (CAP), he declined to pursue it: "NLM doesn't have patients". In his view, the Library lacked the mission, the expertise, and the source data to develop and maintain terminology for clinical systems.

Yet, by the time Lindberg retired in 2015, NLM had been the Central Coordinating Body for Clinical Terminology Standards within the Department of Health and Human Services (HHS) for 11 years [5]. NLM funded the maintenance and free dissemination of two international standards, Logical Observations Identifiers Names Codes (LOINC) and SNOMED CT. NLM also produced RxNorm, the U.S. standard for clinical drugs; the distributor of DailyMed, a database of standard structured product labels for drugs submitted to FDA; and became the developer of the Value Set Authority Center, terminology subsets, and

\footnotetext{
* Corresponding author: Clement J. McDonald M.D., Office of the Director, National Library of Medicine, 8600 Rockville Pike, Bethesda, MD 20894, USA. E-mail: clemmcdonald@mail.nlm.nih.gov.
} 
other tools for facilitating the use of standards in U.S. electronic health records and research data [e.g., 6-9]. NLM was instrumental in the development of the Uniform Code of Units of Measure (UCUM) computable standard, an electronic standard for newborn screening reports, and a database of common data elements (CDEs) for biomedical research [10-12].

This chapter describes how NLM became one of many significant players in U.S. efforts to demonstrate the value, and increase the use of, electronic health records (EHRs) and their supporting standards and then to mandate their use [Endnote 1]. Many factors contributed to this outcome including: the Unified Medical Language System (UMLS); Lindberg's pre-NLM informatics and health services research contacts; and helpful actions by the Institute of Medicine (IOM) (now National Academy of Medicine); the U.S. Congress, HHS, and other federal agencies. Other contributions included: Lindberg's appointment as the first Director of the National Coordinating Office for High Performance Computing and Communications (HPCC); and his decisions to use NLM's authorization to "engage in such other activities as the Secretary [of HHS] determines appropriate and as the Library's resources permit [13-16]".

\section{The UMLS project gives NLM special expertise}

When Lindberg became NLM Director in 1984, he expected an enormous expansion in the universe of electronic information and data applicable to health care and biomedical research. He initiated the UMLS project in 1986 to facilitate development of advanced information systems that could retrieve and integrate related information from disparate electronic sources, e.g., patient records, literature databases, databanks, irrespective of differences in the terminologies used within them [17].

Following a 1986-1988 exploratory period, NLM and Lexical Technology, Inc. (LTI), a UMLS research contractor, built the first version of the UMLS Metathesaurus, a novel knowledge source intended for use by system developers, in 1989-1990 [13]. Building the Metathesaurus involved: analyzing then underspecified semantics of multiple biomedical vocabulary sources; converting relatively primitive machine-readable versions to a common fully specified relational format; using advanced lexical matching methods and human experts to group synonymous terms and codes into concepts; and assigning each concept at least one Semantic Type, e.g., Disease or Syndrome. This process gave NLM specialized knowledge of the content, structure, and informatics properties of multiple terminologies and code sets. As additional vocabulary sources were incorporated into editions of the Metathesaurus, NLM's understanding of their strengths and weaknesses and their degree of overlap deepened.

Lindberg's UMLS Project Director, Betsy Humphreys M.L.S., fielded many questions about the Metathesaurus' purpose and characteristics. In the process, Humphreys learned why a well-structured, freely available clinical terminology standard was needed for EHRs and why the standardization of EHRs would make the UMLS goals easier to achieve.

\section{The Institute of Medicine and the U.S. Congress increase NLM's focus on health services research}

In 1986, a Council on Health Care Technology was established at the Institute of Medicine (IOM), U.S. National Academy of Sciences in response to federal legislation [Endnote 2]. Among other responsibilities, the Council was to develop a clearinghouse for information on health care technologies and technology assessments, broadly defined. Morris Collen M.D., a member of the Council's Information 
Panel, encouraged the group to "talk to Don Lindberg" for advice and to avoid duplicating NLM services. Lindberg was known to the health services research (HSR) and technology assessment community as the previous principal investigator of the National Special Emphasis Center on Health Care Technology, an HSR center funded by the National Center for Health Services Research (NCHSR) in the 1970s [14].

Lindberg joined the Council's Information Panel. Humphreys directed a comparison of the contents of the Council's draft - Medical Technology Assessment Directory: A Pilot Reference to Organizations, Assessments, and Information Resources - with the coverage of NLM services. Although deficiencies in NLM coverage were noted, the analysis showed expansion of existing NLM resources could costeffectively satisfy many of the information needs related to technology assessment [18]. The 1989 legislation establishing the Agency for Health Care Policy and Research (AHCPR) (and eliminating the Council and NCHSR) assigned tasks to NLM to be supported by a funds transfer from AHCPR. As NLM's engagement with the HSR community increased, Humphreys realized both the UMLS and standardized EHRs could lead to better data for HSR.

As desired by Lindberg and AHCPR - and strongly advocated by the Association for Health Services Research (AHSR) - Congress gave NLM direct authorization and appropriated $\$ 8$ million to establish the National Information Center for Health Services Research and Health Care Technology (NICHSR) in 1993. Lindberg appointed Humphreys NLM Assistant Director for Health Services Research Information (concurrent with her position in Library Operations). Lindberg, Humphreys, and AHSR believed that a major goal for NLM's NICHSR was "to contribute to the information infrastructure needed to foster patient record systems that can produce useful health services research data as a by-product of current health care [19]". This provided an explicit rationale and budgetary support for increased NLM involvement in health data standards work, including relevant additions to the UMLS.

\section{NLM develops a position on achieving U.S. clinical terminology standards}

In the early 1990s, the IOM, the American Hospital Association (AHA), the health insurance industry, HHS, and standards development organizations all took steps to sharpen the U.S. focus on electronic data interchange, EHRs, and their supporting standards. As the 1992 U.S. Presidential election approached, the Clinton campaign, with its focus on health care reform, encouraged the U.S. informatics community to develop policy positions.

Due to Lindberg's expertise and the UMLS project, NLM was invited to participate in many standardsrelated activities. Lindberg was a federal liaison to the IOM Committee on Improving the Patient Record in Response to Increasing Functional Requirements and Technological Advances, chaired by Don Detmer M.D. Many informatics pioneers contributed to its landmark 1991 report - The ComputerBased Patient Record: An Essential Technology for Health Care [20]. Humphreys served on the study's Technical Subcommittee and soon as the NLM representative to many other committees, including the Computer-Based Patient Record Institute (CPRI) and the American National Standards Institute (ANSI) Healthcare Informatics Standards Planning Panel, formed in 1991 to coordinate U.S. health data standards activities [21].

Given her representation of NLM, and sometimes the National Institutes of Health (NIH) as a whole, in discussions about EHRs and standards, Humphreys consulted with Lindberg to develop an NLM position on what was needed to achieve U.S. clinical terminology standards. By early 1992, they agreed NLM should promote the following U.S. federal health data standards agenda: 
(1) establish a U.S. federal mechanism for selecting standards applicable to all U.S. health care and public health entities

(2) select the best available set of vocabularies as target U.S. standards

(3) provide ongoing federal support for maintenance, enhancement, and free dissemination of the selected vocabularies

(4) support testing and feedback from real clinical settings before any federal mandate for use.

Lindberg and Humphreys had no firm expectation about the specific role NLM would play in making these ideas a reality.

The ideas were not original to NLM, but the emphasis on the necessity for a federal selection mechanism and federal support for maintenance and free dissemination of terminologies was. Voluntary adoption of terminology standards was unlikely given the diversity of interests in U.S. health care. Congressional action was needed because no federal agency had the authority to impose common standards across U.S. health care and public health. However, such action looked possible in the early 1990s, given the Clinton campaign's health care focus. NLM saw the necessity to select a limited set of existing terminologies as target standards to focus development and testing and make them fit for purpose sooner. NLM also was convinced federal support for maintenance and free dissemination was necessary to achieve widespread adoption of clinical terminology standards. Uncertainty about future price increases and intellectual property restrictions would discourage use. Of course, it would be important to promote use and improve the target terminology standards before mandating them.

Once NLM had an agreed position on any topic, Lindberg was comfortable giving a designated senior staff member, in this case Humphreys, leeway in deciding how, when, and where to pursue it. Lindberg's primary stipulation was that, in this arena, NLM should always proceed in cooperation with other federal agencies.

\section{The HPCC initiative provides new opportunities for promoting EHRs and standards}

In 1992, Lindberg became the first Director of the National Coordination Office for HPCC, which was part of the President's Office of Science and Technology Policy, (serving concurrently as NLM Director) [15]. This appointment led to substantial funding to support health applications of HPCC technologies; acceleration of NLM use of high-speed communications and web technology, including in UMLS construction and distribution; and a request from HHS to promote public health involvement in the emerging National Information Infrastructure (NII) and health data standardization. These created opportunities to advance EHRs and NLM's standards agenda.

In 1993, NLM solicited proposals for projects that could demonstrate the integration of HPCC technologies into health care applications, including "test bed networks for linking hospitals, clinics, doctor's offices, medical schools, medical libraries, and universities to enable health care providers and researchers to share medical data and imagery". Twelve contracts were awarded by April 1994 [22]. In September 1994, NLM, in partnership with AHCPR, awarded five of the eventual eight cooperative agreement grants for research on aspects of EHRs. In announcing them, Lindberg said, "Computer-based patient records are critical to improving the quality and reducing the cost of health care. Much work has been done on electronic patient records, but no fully satisfactory, complete system exists as yet". The new awards "will help foster development of working systems suitable for both inpatient and outpatient care, 
and capable of providing data useful in health services research, including technology assessment and outcomes research [23]”. Several of the awards were focused on terminology for patient data.

- In 1994, NLM added the SPECIALIST lexicon and lexical programs to the UMLS release. In combination with the UMLS Metathesaurus and Semantic Network,

the two services provided powerful tools for matching local terminology to controlled vocabularies and code sets (and revolutionary for biomedical natural language processing) [24].

- In 1995, NLM provided UMLS resources via an Internet server with a Web interface, a command line interface for batch processing, and an application programming interface (API) [25]. This provided a platform for NLM and AHCPR to engage the cooperative agreement partners and others to conduct a large-scale test to determine how well existing biomedical vocabularies covered terminology needed for EHRs [26]. In December 1994, Lindberg and Clifton Gaus Sc.D., AHCPR Administrator, opened a two-day meeting at NLM to identify the set of vocabularies to be included in the test and "to advance the broader agenda of establishing a reasonable starting point for the development and maintenance of a "standard" vocabulary for use in computer-based patient records" in the U.S [27,28]. One presenter had never seen "so many vocabulary nerds in one room". Lindberg was definitely an outlier.

Also in 1994, after the Clinton health reform failed, Philip Lee M.D., Assistant Secretary for Health (ASH), and Roz Lasker M.D., Deputy Assistant Secretary for Health (Policy), established a Public Health Data Policy Coordinating Committee to provide a public health voice on data issues to balance the perspective of the Health Care Financing Administration (HCFA). Humphreys attended a preliminary meeting with Lasker and saw an opportunity to advance NLM's position on the importance of clinical data standards to research and public health and the need for federal support for them. Humphreys was appointed the NIH representative to the committee, setting a precedent for NLM's inclusion in all subsequent HHS health data standards committees. The committee's agenda included consideration of the federal role in supporting data standards, the need for greater public health participation in standards development, and the poor information technology infrastructure in public health departments.

Lee and Lasker met with Lindberg to discuss how to promote collaboration between the medical informatics and public health communities, achieve more public health involvement in the NII, and advance public health participation in data standardization. Lee and Lindberg had been colleagues since the time when both directed NCHSR-funded centers in the 1970s. Lindberg suggested an invited meeting as an initial step. On April 19, 1995 (the day of the Oklahoma City bombing), NLM, the Office of the ASH, the Centers for Disease Control and Prevention (CDC), and AHCPR convened an invited conference, "Making a Powerful Connection: The Health of the Public and the National Information Infrastructure" and a smaller strategy session on April 20. The 120 conference attendees included representatives of federal agencies, foundations, state and local public health departments, associations, NLM-funded informatics training programs, and the National Network of Libraries of Medicine (NNLM). The meeting and the resulting report and recommendations from the Public Health Data Policy Coordinating Committee had significant immediate and long-term effects, including on NLM informatics training and research programs and standards activities [29-31].

\section{NLM HPCC funding triggers development of a health information exchange}

NLM's 1993 request for proposals for HPCC applications "provided the spark", and in April 1994 NLM initially funded the development of the Indianapolis Network for Patient Care (INPC), later renamed 
the Indiana Network for Patient Care [32]. Clement McDonald M.D., then Director of the Regenstrief Institute, was the principal investigator (PI) on the proposal to integrate medical data from three inner city Indianapolis hospitals into the Regenstrief Medical Record System. The technical reviewers were impressed by the strong letters of support from the initial local participants, Wishard Memorial, Indiana University, and Methodist Hospitals which were also competitors. Lindberg was not surprised. ("Clem has been there a long time. They trust him”.) Lindberg preferred to fund novel applications in environments conducive to rapid production of working systems.

In the INPC, the data from each contributing organization was sent to the Regenstrief Institute using HL7 v2 messages and stored respectively in their own separate file systems. All the file systems had the same database structure and were tied to a single common term dictionary. A record linkage system connected patient registration records together as they were received from each site. The net result was that providers at each hospital could see a patient's data from all three hospitals in one uniform view as though from a single system, but only when a patient was currently under their care as verified by their hospital's registration system.

With additional NLM HPCC funding in 1996, the network expanded to five institutions and 12 hospitals all within Indianapolis. A connection to public health departments was established at NLM's request. The funding was approved by Lindberg as the best way to create a demonstration of electronic notifiable disease reporting. The INPC was a hit with care providers, especially emergency room (ER) providers [33]. Analysis of INPC data showed considerable overlap among the patients seen in different ERs in the same region [34].

The INPC was the first operational Health Information Exchange (HIE) and provided a model for many HIEs that followed. A web application called CareWeb, still in operation, gave providers a unified view of their patients' medical data generated at any hospital. It included almost every kind of structured test result, as well as narrative discharge summaries, operative reports, and other kinds of notes. In its later years, it presented radiology images and EKG tracings from some institutions. A second application called Docs4Docs delivered all diagnostic reports and provider dictation to the provider's office. The INPC was the first to deliver electronic notifiable disease test results to a state public health department (Indiana's) - four times more of them, faster and with more complete detail than the manual system [35].

The modest Indianapolis HIE that began life in 1994 with NLM funding that Lindberg obtained from the HPCC program has continued to operate and grow. Today, the Indiana Health Information Exchange (IHIE) serves 20,000 care providers from Indiana and adjacent states and encompasses 12 billion structured observations and hundreds of millions of narrative reports and radiology images from more than 100 health care organizations - all in the service of better health care [36].

\section{Health information exchange highlights the need for a new standard}

The INPC provided an early visible demonstration of the value of health data standards and the need for one more of them. The Indiana investigators could not have created the INPC without the HL7 v2 message standard. Fortunately, in 1994 HL7 v2 had existed for more than seven years and had been adopted by many health care systems. At that time, HL7 did not require use of any specific code system to identify test results, and there was no viable candidate for practical adoption in the U.S. Each hospital invented its own idiosyncratic code system. 
To build the initial INPC, Regenstrief had to hand map hospital specific codes to the Regenstrief local "standard" in the term dictionary. This was labor intensive and not easily scalable to the anticipated expansion of the INPC, let alone broader efforts to merge data for health care, research, and public health.

Foreseeing this problem prior to receiving HPCC funding in April 1994, Regenstrief organized an international committee of medical informatics and laboratory experts to develop standard names and codes for clinical observations, starting with laboratory test results. If all producers of test results used standard names and codes in their HL7 messages, the results could easily be merged into any EHR or HIE. As the committee began its work, McDonald submitted an application in response to the joint NLMAHCPR request for cooperative agreement proposals for research on requirements for networked EHRs, including new, practical approaches to vocabulary issues. The AHCPR funded it in September 1994, thus providing additional support for early LOINC development.

Stanley Huff M.D., co-chair of the LOINC committee, gave the LOINC presentation at the NLMAHCPR meeting in December 1994 that chose the vocabularies to be included in the planned large scale vocabulary test [27]. His presentation introduced most of the attendees to LOINC for the first time. The consensus reached was to include in the test all vocabularies already in the UMLS, plus the rest of SNOMED, the UK Read Codes, and LOINC. Version 1 of LOINC was released in April 1995 [37].

\section{HIPAA changes the standards playing field}

The Health Insurance Portability and Accountability Act of 1996 (HIPAA) gave the Secretary of HHS responsibility to make regulations to establish standards for electronic transmission of administrative health transactions, code sets, and security, among others. Standards were to be adopted within 18 months, with compliance required two years later. Non-compliance carried penalties. The Secretary was required to take advice from National Committee on Vital and Health Statistics (NCVHS) in establishing HIPAA standards. The law expanded the NCVHS and charged it to "study the issues related to the adoption of uniform data standards for patient medical record information and the electronic exchange of such information" and make recommendations by 2000 [38].

Finally, there was a federal mechanism for selecting administrative data standards applicable to all U.S. health care entities and the potential for extending it to clinical data standards. The selection of existing standards was specified as the preferred approach, and, in language Humphreys helped to draft, the Secretary was required to "establish efficient and low-cost procedures for distribution (including electronic distribution) of code sets" and their modifications [39]. Inclusion in the UMLS would soon be viewed as important to meeting this requirement.

NLM's first contribution to HIPAA's implementation was funding a short extension to a Lindbergcommissioned National Academies study on maintaining privacy and security in health care applications of the National Information Infrastructure. This enabled the committee to make its 1997 report, For the Record: Protecting Electronic Health Data, directly suitable as the basis for HIPAA security standards [40]. Lindberg had charged the study committee to visit hospitals and a public health department, a very unusual requirement for an Academies study at the time. Lindberg thought the computer scientists in the group should see health data systems before making recommendations for them.

HIPAA was a milestone on the road to health data standards, but it came with an enormous workload. When Humphreys was asked to co-chair the HHS Coding and Classification Implementation Team, Lindberg and she decided that helping with the administrative standards work would enable NLM to influence later recommendations on EHR standards. NLM supported the NCVHS Workgroup on 
Computer-Based Patient Records (McDonald was a member) as it developed the 2000 report on standards for EHR information. In 1999, CAP and the U.K. National Health Service announced plans to merge SNOMED and the Read Codes, thus simplifying U.S. clinical terminology selection.

Humphreys proposed creating an example of federal support for maintenance of a required terminology. Lindberg approved if other federal agencies participated. In 1999, NLM issued a contract to support the ongoing maintenance of LOINC, with financial contributions from the U.S. Department of Veterans Affairs (VA), the U.S. Department of Defense (DOD), and HCFA. The case for LOINC was relatively easy; it was freely available and slated for mandate in the HIPAA claims attachment transaction. As of 2021, NLM still supports LOINC maintenance and expansion, as do other agencies, although no HIPAA claims attachment standard yet exists. Lindberg's 1999 view of health data standards work appeared in NLM's Long Range Plan for 2000-2005. It included a program plan to "work with other Federal agencies and outside organizations to support the establishment, ongoing maintenance, testing, and use of health data standards to enhance the quality of care and improve the data available for research [41]".

Early in 2000, the U.S. National Cancer Institute (NCI), VA, and CDC approached Humphreys about NLM negotiating a U.S. government-wide license for use of SNOMED. A federal-only license did not address a national need to exchange and aggregate health data across federal, state, and private sector entities, but Humphreys consulted with Lindberg about trying for a U.S. nationwide license. The NIH budget was then doubling so the suggestion's timing was good. Lindberg was firm that NLM needed to launch new programs, e.g., consumer health, ClinicalTrials.gov, with the increase, not just do more of the same. Given HHS' backing, Lindberg was willing for NLM to try to negotiate a novel license arrangement and to consider it one of NLM's new programs, if a reasonable deal were reached. In June 2000, NLM issued a sole-source procurement to CAP for a nationwide license for SNOMED, with experts from other agencies serving as technical advisors.

\section{The George W. Bush administration embraces EHRs and standards}

The July 2000 NCVHS report on standards for EHR information recommended the HHS Secretary accept proposed criteria for selecting clinical data standards and forthcoming recommendations of clinical standards for adoption by government agencies. This was a HIPAA-like process, minus regulation, to establish target U.S. standards and promote testing before mandating use. The report recommended "government-wide licensure or comparable arrangements" to make terminologies available "at little or no cost" and action on drug terminology [42]. There was no HHS response in the waning days of the Clinton Administration.

When George W. Bush won the 2000 U.S. election, some worried about diminished interest in health data standards. As it happened, Tommy Thompson, the new HHS Secretary, expressed strong support for standards very early in his tenure, following a meeting with John Lumpkin M.D. and Don Detmer M.D., current and former NCVHS chairs. The staff in the Office of the HHS Assistant Secretary for Planning and Evaluation, VA, and DOD succeeded in focusing the U.S. Office of Management and Budget e-Gov health initiative on government-wide adoption of clinical data standards. The Consolidated Health Informatics (CHI) e-Gov project became the vehicle for reviewing NCVHS recommendations and recommending adoption of standards by HHS, VA, and DOD. NLM was a CHI participant.

The negotiations for the SNOMED license were considered a critical CHI activity. Among the first standards to go through this process and be adopted by HHS, VA, and DOD in 2003 were LOINC and 
HL7. By that time, LOINC had grown from 5900 names and codes, primarily for laboratory test results, to more than 34,000, a fifth of which were clinical observations, document types, and survey instruments.

Meanwhile at NLM, Stuart Nelson M.D. was defining a standard form for the names of "clinical drugs" to enable accurate linking of drug terminology in the UMLS [43]. The work built on previous HL7 efforts to define a standard form useful in clinical decision support. Commercial drug information sources, e.g., First DataBank, had prompted and participated in the HL7 project. Nelson's approach to solving the UMLS Metathesaurus construction problem was also a feasible way to build a standard clinical drug vocabulary to address NCVHS concerns and enable effective exchange and aggregation of EHR data.

Nelson presented the RxNorm proposal for Lindberg's approval, describing the planned electronic transmission of source data (structured drug product labels (SPLs) to NLM by the Food and Drug Administration (FDA) and complementary VA work on clinical properties of drugs, e.g., physiologic effects. Lindberg was enthusiastic about the project and collaboration with FDA and VA. He asked one typical question: "Will RxNorm be useful if the VA work doesn't proceed?" The answer was "yes" and RxNorm was first released in the 2002 UMLS and separately in 2004 [44]. In November 2005, NLM released DailyMed, the official distribution mechanism for current SPLs submitted to FDA by companies [45].

By mid-2002, NLM and CAP had agreed on the terms for a U.S. nationwide SNOMED license but remained far apart on price. NLM sent a letter ending the negotiations, responding to a CAP communication about a lowest acceptable figure. Former Congressman John Porter soon called Lindberg to ask for a meeting with CAP representatives and himself to discuss a way forward. Lindberg readily agreed ("I'm always willing to meet") and included Humphreys and Donald King M.D., NLM Deputy Director for Research and Education. The discussion led to a new round of talks, with a fixed end date of January 15, 2003 suggested by Porter. Helped by King's communication with CAP leaders, a deal was reached in December 2002 at a price in NLM's range. A one-time fee for a perpetual license was covered by contributions from DOD, VA, and many HHS agencies. The annual maintenance fees were paid by NLM [46]. Secretary Thompson assigned the contribution level to each HHS agency. NLM and CAP signed the contract on July 1, 2003, and the huge job of incorporating SNOMED into the UMLS began.

The Secretary announced the SNOMED license at an HHS consensus conference on Developing the National Health Information Infrastructure (NHII) in Washington DC on July 1, 2003 [47,48]. HHS and NLM received universal praise, influencing subsequent Administration actions in 2004. These included: the Executive Order setting a goal for EHRs for the majority of Americans by 2014 and establishing the National Coordinator for HIT; the designation of NLM as the HHS central coordinating body for clinical terminology standards; and the placement at NLM of a short-term Commission on Systematic Interoperability required by the Medicare Modernization Act of 2003 [5,49]. Both SNOMED and RxNorm went through the CHI process and were adopted by HHS, DOD, and VA in 2004 [50]. In 2005, the National Coordinator for HIT funded a new Health IT Standards Panel, with Humphreys on the Executive Board, and the HHS Secretary, now Michael Leavitt, another strong supporter of standards, established the American Health Information Community (AHIC), a federal advisory committee focused on a broader agenda, including adoption of EHRs.

The U.S. nationwide license for SNOMED inspired the business model and licensing terms for the International Health Terminology Standards Development Organization (now trading as SNOMED International). The U.K. led its formation in 2007 to acquire SNOMED from CAP, manage its maintenance, share costs proportionally among member countries, and encourage international adoption and use in vendor products. NLM represented the U.S. as one of nine founding members. There are 40 member countries today [51]. 


\section{Use of EHRs and supporting standards becomes mandatory}

Lindberg's 2005 view of EHRs was explained in the closing section of the 2006-2016 NLM long range plan: "As reflected in special Presidential and Departmental initiatives, the country badly needs and wants better electronic health records. ... We expect the need for electronic record systems to become more acute in the future. NLM should continue to contribute significantly to the solution". EHRs, health data standards, and clinical research data were central to one of the plan's four broad goals: "Integrated biomedical, clinical, and public health systems that promote scientific discovery and speed the translation of research into practice". A specific recommendation called upon NLM to promote the development of next-generation EHRs to support care, research, and public health [52].

Lindberg's interest in EHRs and standards was evident in McDonald's 2006 appointment as Scientific Director and Director of the Lister Hill National Center for Biomedical Communications (LHC). McDonald took the position only after confirming that his continuing service on the LOINC Committee would not cause a conflict of interest. Lindberg believed in Personal Health records (PHRs), as earlier demonstrated by his positive view of health smartcards when serving as U.S. National Coordinator of G-7 Healthcare applications (1996-2000). "A person should be able to put all of his/her data into their personal health record. It is their data so they should have it and be able to know exactly what was going on with their health and to pass it to whomever they wanted [53]". Lindberg urged McDonald to develop an NLM PHR and was disappointed when efforts to locate a hospital partner to test his standards-based PHR application with patients failed. (The initially interested hospitals were merged or acquired.) However, Lindberg's original idea still lives. At present, more than 800 institutions (including hospital networks and specialty practices) can deliver a patient's health care data to their iPhone. The Apple Health PHR is then able to receive those data using HL7 FHIR, present them in a user-friendly fashion, or display their underlying standard structures and codes at the click of a button.

In 2007, as HHS inquiries to NIH about health IT standards increased, Elias Zerhouni M.D., Director of NIH (2002-2008), asked Lindberg to chair a new Trans-NIH Biomedical Informatics Coordinating Committee (BMIC). Lindberg saw the assignment as improving communication about current projects related to clinical and bioinformatics at NIH and surfacing matters warranting consideration by NIH policymakers. The meetings were interesting and popular. The presentations and discussions led BMIC to establish the NIH Common Data Element (CDE) repository and create guidance for research data sharing plans [54]. In addition to updating BMIC members on the rapidly changing federal health IT picture, NLM staff used BMIC to promote use of health IT standards in clinical research, another longstanding NLM priority.

Overall, there is no doubt Lindberg would be pleased by recent progress in this area, e.g., the $2019 \mathrm{NIH}$ guidance on use of HL7 Fast Healthcare Interoperability Resources (FHIR) and in 2020, on use of the coding/systems specified the U.S. Core Data for Interoperability (USCDI), including LOINC, RxNorm, and SNOMED [55,56]

McDonald arrived just in time to add his expertise to NLM's National Center for Biotechnology Information (NCBI) to implement the AHIC Personalized Care Workgroup's recommendations regarding standards for transmitting results of genetic tests and newborn screening in 2007. Ensuring that genetic test data could be incorporated in EHRs was a high priority for Secretary Leavitt. The NLM work involved an expansion of LOINC, input to a draft HL7 implementation guide, and development of RefSeqGene to include reference sequences for recording and interpreting clinically significant genetic variations [57].

At Lindberg's request, the NLM Board of Regents established a work group in September 2008 to assess the usefulness and budget of NLM's health data standards activities and to identify opportunities for NLM 
to advance standards development and deployment further. A significant opportunity arrived in February 2009 with passage of the Health Information Technology for Economic and Clinical Health (HITECH) Act, as part of the American Recovery and Reinvestment Act (ARRA). The latter established the Office of the National Coordinator for Health IT in law, created two new federal advisory committees on health IT policy and standards, and provided monetary incentives for the "meaningful use" of EHRs, which required use of designated clinical data standards. In May 2009, the work group recommended to the Board of Regents that NLM immediately create tools and services to help vendors and users incorporate terminology standards into EHRs and to align terminology value sets with data elements [58].

Once again, a National Academies study commissioned by Lindberg appeared at an opportune moment. Computational Technology for Effective Health Care was published in 2009 in time to influence ideas about "meaningful use" and solicitations for research and development projects supported by timelimited ARRA research funds, including those issued by NLM and the U.S. Office of the National Coordinator [59].

Although many thought they had been working hard on federal health IT priorities, the pace became frenetic in 2009. Standards already adopted for U.S. government-wide use under the CHI process were obvious candidates for selection as national HITECH "meaningful use" standards but required hearings and rulemaking to attain that status. At the same time, regulations were being developed for the incentive program and other HITECH provisions. Questions inevitably arose about whether LOINC, RxNorm, or SNOMED were suitable for a particular "meaningful use" purpose and whether there were sufficient tools and services to make implementation feasible. NLM's priority was to do whatever possible to ensure an affirmative answer to all the questions.

\section{Concluding thoughts}

By 2011, the U.S. had established national clinical data standards. Among them were LOINC, RxNorm, and SNOMED - all regularly updated and freely available. In broad strokes, what NLM outlined as its position on clinical terminology standards in 1992 had occurred. The desired result arrived two decades later with little doubt about NLM's primary role. Lindberg's vision for the UMLS, his willingness to take unprecedented steps carefully and with allies, and his long tenure at NLM were essential to this outcome.

\section{Endnotes}

[1] This chapter covers a piece of the much larger history of clinical data standards development and adoption in the U.S. It mentions by name only a few of the literally hundreds of people and the dozens of organizations that contributed to the events described. Some (but not all) additional contributors are among the authors of sources cited in the references.

[2] There had been earlier U.S. legislative attempts to establish a robust system of health technology assessment, amid concerns about rising Medicare costs and widespread adoption of new technologies without adequate evidence of their safety and efficacy. See: Blumenthal D. Federal Policy toward health care technology: the case of the National Center. Milbank Mem Fund Q Health Soc. 1983 Fall;61(4):584613. doi: $10.2307 / 3349874$. 


\section{References}

[1] B.L. Humphreys, De facto, de rigueur, and even useful: Standards for the published literature and their relationship to medical informatics. in: Proceedings; Fourteenth Annual Symposium on Computer Applications in Medical Care, R.A. Miller (ed.), IEEE Computer Society Press, Washington, 1990, pp. 2-8.

[2] S. Kotzin and P.L. Schuyler, NLM's practices for handling errata and retractions, Bull Med Libr Assoc 77(4) (1989), 337342.

[3] B.L. Humphreys and C.R. Kalina, Revising the American national standard for permanence of paper (ANSI Z39.48-1984): Changing market ractors, changing paper technology, and new research questions. in: Proceedings 1991 Papermakers Conference, Seattle, WA, April 8-10 TAPPI Press, 1991, pp. 243-249.

[4] J. Beck, NISO Z39.96. The journal article tag suite (JATS): what happened to the NLM DTDs? J Electron Publ 14(1) (2011), 106. doi:10.3998/3336451.0014.106.

[5] T.G. Thompson, , (Secretary of Health and Human Services). Letter to: Lumpkin J. M.D. (Chair, National Committee on Vital and Health Statistics). 2004 September 22 [cited 2021 August 16]. Available from: https://ncvhs.hhs.gov/wpcontent/uploads/2014/05/040922lt.pdf.

[6] O. Bodenreider, R. Cornet and D.J. Vreeman, Recent developments in clinical terminologies - SNOMED CT, LOINC, and RxNorm, Yearb Med Inform 27(1) (2018), 129-139. doi:10.1055/s-0038-1667077.

[7] O. Bodenreider, D. Nguyen, P. Chiang, P. Chuang, M. Madden, R. Winnenburg et al., The NLM value set authority center, Stud Health Technol Inform 192 (2013), 1224, PMC4300102.

[8] L. Peters, J. Mortensen, T. Nguyen and O. Bodenreider, Enabling complex queries to drug information sources through functional composition, Stud Health Technol Inform 192: (2013), 692-696, PMCID: PMC4303373.

[9] Health information technology and health data standards at NLM. [Internet] [cited 2021 August 28].

[10] UCUM-LHC. A uniified code for units of measure softeware library from the National Library of Medicine. [Internet] [cited 2021 September 1]. Available from: https://ucum.nlm.nih.gov/ucum-lhc/.

[11] Newborn screening coding and terminology guide. National Library of Medicine (U.S.). [Internet] [cited 2021 September 2021]. Available from: https://lhncbc.nlm.nih.gov/newbornscreeningcodes/nb/sc/about.html.

[12] NIH Common Data Elements (CDE) repository. [Internet] [cited 2021 September 1]. Available from: https://cde.nlm. nih.gov/home.

[13] B.L. Humphreys and M.S. Tuttle, Something new and different: the Unified Medical Language System. in: Transforming Biomedical Informatics and Access to Health Information: Don Lindberg and the U.S. National Library of Medicine, B.L. Humphreys, R.A. Miller, E.R. Siegel and R.A. Logan (eds), IOS Press, Amsterdam, 2021.

[14] L.C. Kingsland III and C.A. Kulikowski, A scientific mind embraces medicine: Donald Lindberg's education and early career. in: Transforming Biomedical Informatics and Access to Health Information: Don Lindberg and the U.S. National Library of Medicine, B.L. Humphreys, R.A. Logan, R.A. Miller and E.R. Siegel (eds), IOS Press, Amsterdam, 2021.

[15] M.J. Ackerman, S.E. Howe and D.R. Masys, Don Lindberg, high performance computing and communications, and telemedicine. in: Transforming Biomedical Informatics and Access to Health Information: Don Lindberg and the U.S. National Library of Medicine, B.L. Humphreys, R.A. Logan, R.A. Miller and E.R. Siegel (eds), IOS Press, Amsterdam, 2021.

[16] Title 42. U.S.C. § 286. 2011. National Library of Medicine (b)(8). [cited 2021 September 1]. Available from: https://www. nlm.nih.gov/about/nlmlaw.html.

[17] D.A.B. Lindberg, B.L. Humphreys and A.T. McCray, The unified medical language system, Meth Inf Med 32: (1993), 281-291. doi:10.1055/s-0038-1634945.

[18] Institute of Medicine (US). Council on Health Care Technology. Medical Technology Assessment Directory: A Pilot Reference to Organizations, Assessments, and Information Resources, C. Goodman (ed.), National Academies Press (US), Washington (DC), 1988, pp. v, x, xxvii-iii. Available from: https://www.ncbi.nlm.nih.gov/books/NBK218376/.

[19] NLM launches new National Information Center on Health Services Research and Health Care Technology. NLM News. 1993; 48(9-10):2-3.

[20] The computer-based patient record: an essential technology for patient care. Revised edition. Dick R., Institute of Medicine (US). Committee to improve the patient record. Steen E., Detmer D.E., editors. Washington DC: National Academies Press; 1997. Available from: https://www.ncbi.nlm.nih.gov/books/NBK233047/.

[21] C.J. McDonald ANSI's Health Informatics Planning Panel (HISPP) - The Purpose and Progress, G.J.E. De Moor et al. (ed.), IOS Press, Amsterdam, 1993, pp. 14-19.

[22] New contracts link health care and advanced computing. NLM Newsline. 1994: 49(2). [Internet] [cited 2021 August 16]. Available from: https://www.nlm.nih.gov/archive/20040422/pubs/nlmnews/marapr94.html. 
[23] New awards focus on computerized medical records. NLM Newsline. 1994; 49(5). [Internet] [cited 2021 August 16]. Available from: https://www.nlm.nih.gov/archive/20040422/pubs/nlmnews/sepoct $94 . h t m l$.

[24] A. T. McCray, S. Srinivasan and A.C. Browne, Lexical methods for managing variation in biomedical terminologies, Proc Annu Symp Comput Appl Med Care (1994), 235-239, PMCID: PMC2247735.

[25] A.T. McCray, A.M. Razi, A.K. Bangalore, A.C. Browne and P.Z. Stavri, The UMLS knowledge source server: A versatile Internet-based research tool, Proc AMIA Annu Fall Symp 1996: 164-168, PMCID: PMC2233094.

[26] B.L. Humphreys, W.T. Hole, A.T. McCray and J.M. Fitzmaurice, Planned NLM/AHCPR large-scale vocabulary test: Using UMLS technology to determine the extent to which controlled vocabularies cover terminology needed for health care and public health, J Am Med Inform Assoc 3(4) (1996), 281-287. doi:10.1136/jamia.1996.96413136.

[27] Vocabularies for computer-based patient records: identifying candidates for large scale testing. Minutes of a meeting sponsored by National Library of Medicine and Agency for Health Care Policy and Research, December 5-6, 1994. [Internet] [cited 2021 August 20]. Available from: http://www.nlm.nih.gov/archive/20040721/lo/minvocab.html.

[28] B.L. Humphreys, A.T. McCray and M.L. Cheh, Evaluating the coverage of controlled health data terminologies: report on the results of the NLM/AHCPR Large Scale Vocabulary Test, J Am Med Inform Assoc 4(6) (1997), 484-500.

[29] R.D. Lasker, B.L. Humphreys and W.R. Braithwaite, Making a powerful connection: The health of the public and the national information infrastructure. A report of the Public Health Service Data Policy Coordinating Committee. [Internet]. Washington, DC: US Public Health Service, 7 Jul 1995. [cited 2021 August 20]. Available from: http://www. nlm.nih.gov/pubs/staffpubs/lo/makingpd.html.

[30] B.L. Humphreys, Building better connections: the National Library of Medicine and public health, J Med Libr Assoc 95(3) (2007), 293-300. doi:10.3163/1536-5050.95.3.293.

[31] W.A. Yasnoff, J.M. Overhage, B.L. Humphreys et al., A national agenda for public health informatics: Summarized recommendations from the 2001 AMIA Spring Congress, JAm Med Inform Assoc 7: (2001), 1-21. doi:10.1136/jamia.2001.0080535.

[32] C.J. McDonald, J.M. Overhage, M. Barnes, G. Schadow, L. Blevins, P.R. Dexter et al., The Indiana network for patient care: a working local health information infrastructure. An example of a working infrastructure collaboration that links data from five health systems and hundreds of millions of entries, Health Aff (Millwood) 24(5) (2005), 1214-1220. doi:10.1377/hlthaff.24.5.1214.

[33] J.T. Finnell and J.M. Overhage, Emergency medical services: The frontier in health information exchange, AMIA Annu Symp Proc 2010: (2010), 222-226.

[34] J.T. Finnell, J.M. Overhage and C.J. McDonald, In support of emergency department health information technology, AMIA Annu Symp Proc 2005: (2005), 246-250.

[35] J.M. Overhage, S. Grannis and C.J. McDonald, A comparison of the completeness and timeliness of automated electronic laboratory reporting and spontaneous reporting of notifiable conditions, Am J Public Health 98(2) (2008), 344-350. doi:10.2105/AJPH.2006.092700.

[36] Indiana Health Information Exchange. [Internet] [cited 2021 August 21]. Available from: https://www.ihie.org/.

[37] S.M. Huff, R.A. Rocha, C.J. McDonald, G.J. De Moor, T. Fiers, W.D. Bidgood Jr. et al., Development of the Logical Observation Identifier Names and Codes (LOINC) vocabulary, J Am Med Inform Assoc 5(3) (1998), $276-292$. doi:10.1136/jamia.1998.0050276.

[38] Health Insurance Portability and Accountability Act of 1996. Title XI. Sec. 263 (5)(B)-(C). [Internet] [cited 2021 Aug 29], Available from: https://www.govinfo.gov/content/pkg/PLAW-104publ191/html/PLAW-104publ191.htm.

[39] Health Insurance Portability and Accountability Act of 1996. Title II. Subtitle F. Sec. 1173 (c) (2). [Internet] [cited 2021 Aug 29]. Available from: https://www.govinfo.gov/content/pkg/PLAW-104publ191/html/PLAW-104publ191.htm.

[40] For the record: protecting electronic health information. National Research Council (US). Committee on maintaining privacy and security in health care applications of the National Information Infrastructure. Washington DC: National Academy Press, 1997. [cited 2021 September 1] Available from: https://www.ncbi.nlm.nih.gov/books/NBK233429/.

[41] National Library of Medicine (U.S.). Board of Regents. National Library of Medicine long range plan 20002005. [Bethesda MD]: National Library of Medicine, 2000. p. 19. Available from: https://collections.nlm.nih.gov/ext/ kirtasbse/100963683/PDF/100963683.pdf.

[42] National Committee on Vital and Health Statistics. Report to the Secretary of the U.S. Department of Health and Human Services on uniform data standards for patient medical record information. July 6, 2020. [cited 2021 August 29]. Available from: https://ncvhs.hhs.gov/wp-content/uploads/2014/05/hipaa000706.pdf.

[43] S.J. Nelson, S.H. Brown, M.S. Erlbaum, N. Olson, T. Powell, B. Carlsen et al., A semantic normal form for clinical drugs in the UMLS: Early experiences with the VANDF, Proc AMIA Symp (2002), 557-561.

[44] S.J. Nelson, K. Zeng, J. Kilbourne, T. Powell and R. Moore, Normalized names for clinical drugs: RxNorm at 6 years, J Am Med Inform Assoc 18(4) (2011), 441-448. doi:10.1136/amiajnl-2011-000116. 
[45] DailyMed. [Internet] [cited 2021 September 1]. Available from: https://dailymed.nlm.nih.gov/dailymed.

[46] SNOMED Clinical Terms ${ }^{\circledR}$ To Be Added To UMLS ${ }^{\circledR}$ Metathesaurus ${ }^{\circledR}$. National Library of Medicine, July 1, 2003. [cited 2021 August 31]. Available from: https://www.nlm.nih.gov/research/umls/Snomed/snomed_announcement.html.

[47] HHS launches new efforts to promote paperless health care system. Press Release. National Library of Medicine (U.S.). July 1, 2003. [cited 2021 August 31]. Available from: https://www.nlm.nih.gov/archive/20120510/news/press_ releases/paperlesspr03.html.

[48] W.A. Yasnoff, B.L. Humphreys, J.M. Overhage, D.E. Detmer, P.F. Brennan, R.W. Morris et al., A consensus action agenda for achieving the National Health Information Infrastructure, J Am Med Inform Assoc 11: (2004), 332-338. doi:10.1197/jamia.M1616.

[49] Commission on Systemic Interoperability. Ending the document game: connecting and transforming your health care through information technology. [Internet]. [cited 2021 September 1]. Available from: https://endingthedocumentgame. gov/noflash/index.html.

[50] Consolidated Health Informatics (CHI) Initiative; health care and vocabulary standards for use in federal health information technology systems. 70 Fed Reg. 76287 (December 23, 2005). [Internet] [cited 2021 September 1]. Available from: https://law.gwu.libguides.com/federalregulatory/citations.

[51] SNOMED International. Members. [cited 2021 August 31]. Available from: https://www.snomed.org/our-stakeholders/ members.

[52] National Library of Medicine (U.S.). Board of Regents. charting a course for the 21st Century: NLM's Long Range Plan 2006-2016. [Bethesda MD]: National Institutes of Health, September 2006. [cited 2021 August 31]. Available from: https://collections.nlm.nih.gov/ext/kirtasbse/101290062/PDF/101290062.pdf.

[53] Personal communication to McDonald C.J.

[54] Trans-NIH Biomedical Informatics Coordinating Committee. [Internet] [cited 2021 September 1]. Available from: https://www.nlm.nih.gov/NIHbmic/index.html.

[55] National Institutes of Health (U.S.). Fast Healthcare Interoperability Resources (FHIR) Standard. NIH guide to grants and contracts. NOT-OD-19-122. [Internet]. July 30, 2019. [cited 2021 September 1]. Available from: https://grants.nih.gov/grants/guide/notice-files/NOT-OD-19-122.html.

[56] National Institutes of Health (U.S.). Accelerating clinical care and research through the use of the United States Core Data for Interoperability (USCDI). NIH guide to grants and contracts. NOT-OD-20-146. July 30, 2020 [cited 2021 September 1]. Available from: https://grants.nih.gov/grants/guide/notice-files/NOT-OD-20-146.html.

[57] S. Abhyankar, M.A. Lloyd-Puryear, R. Goodwin, S. Copeland, J. Eichwald, B.L. Therrell et al., Standardizing newborn screening results for health information exchange, AMIA Annu Symp Proc 2010: (2010), 1-5, PMC3041276.

[58] National Library of Medicine (U.S.). Board of Regents. Working Group on Health Data Standards. Interoperable information: enhancing NLM's contribution to the nation's health IT agenda. Final report. Submitted April $23,2009$. Amended and accepted by the NLM Board on May 9, 2009. [cited 2021 August 31]. Available from: https://www.nlm. nih.gov/od/bor/BORHDSWG-report.pdf.

[59] Computational technology for effective health care: immediate steps and strategic directions. In: Stead W.W., Lin H., editors. National Research Council (US), Committee on Engaging the Computer Science Research Community in Health Care Informatics. Washington DC: National Academy Press, 2009. [cited 2021 September 1]. Available from: https://www.ncbi.nlm.nih.gov/books/NBK20640/. 